\title{
INVESTIGATION OF ACID-BASE PROPERTIES OF AROMATIC HYDRAZONES IN BASIC MEDIA AT CONSTANT IONIC STRENGTH
}

\author{
Mirjana S. Jankulovska ${ }^{*}$, Vesna Dimova², Ilinka Spirevska3 \\ ${ }^{1}$ Faculty of Agricultural Sciences and Food, Ss. Cyril and Methodius University in Skopje, Skopje, Macedonia \\ ${ }^{2}$ Faculty of Technology and Metalurgy, Ss Cyril and Methodius University, Skopje, Macedonia \\ 3Institute of Chemistry, Faculty of Natural Sciences and Mathematics, Ss Cyril and Methodius University, Skopje, \\ Macedonia
}

\begin{abstract}
U V$ spectroscopic methods were used in order to determine dissociation constants of some aromatic hydrazones. The acid-base properties of investigated hydrazones were followed in sodium hydroxide media at constant ionic strength of $0.5 \mathrm{~mol} / \mathrm{dm}^{3}$ adjusted with sodium perchlorate. Absorption band with the maximum of $330 \mathrm{~nm}$ was noticed in neutral media. A batochromic shift of this band was observed in basic media, probably due to the dissociation process. The dissociation process took place in one step for four investigated hydrazones and in two steps for the hydrazone with a phenol group in its molecule. The absorbance data from the UV spectra were used for the calculation of dissociation constants. The obtained $p K_{H A}$ values were between 2.11 and 2.62 which suggested that the influence of the substituents is not significant. At the same time, $p K_{H A}$ values were determined graphically from the intercept of the dependence of logI on $\mathrm{pH}$. There are no important differences between calculated and graphically determined dissociation constant values.
\end{abstract}

Key words: Aromatic hydrazones, UV spectroscopy, dissociation, dissociation constants

DOI: $10.21175 / \operatorname{RadProc} .2017 .59$

\section{INTRODUCTION}

The hydrazones are a well-known class of organic compounds with a wide spectrum of application, which is a result of having an azomethine proton $(-\mathrm{NH}-\mathrm{N}=\mathrm{CH}-) \quad[1]$. A number of researchers synthesized and evaluated the biological activities of hydrazones. These compounds possess diverse biological and pharmacological properties such as antimicrobial, anti-inflammatory, analgesic, antifungal, anti-tubercular, antiviral, anticancer, antiplatelet, antimalarial, anticonvulsant, cardio protective, antihelmintic, antiprotozoal, antitrypanosomal, antischistosomiasis and so on [2-6]. On the other hand, hydrazones are useful spectrophotometric reagents because of their selectivity for metal ions [7]. Hydrazones and their metal complexes exhibit a wide spectrum of physiological and pharmacological activities. Due to their physiological activity, they are used as herbicides, insecticides, and plant growth stimulants [8]. Furthermore, hydrazones are also used in industry as plasticizers, polymer stabilizers, antioxidants, polymerization initiators [9]. The dissociation constants of organic compounds like hydrazones play a fundamental role in many analytical procedures such as acid-base titration, solvent extraction, complex formation and ion transport [10]. Moreover, the biological activity of hydrazones depends on the ionic forms in which they exist in the solution. Therefore, determination of dissociation constants in defined media is very important. In the literature, there are different methods for the determination of dissociation constant values such as potentiometric titration, NMR spectroscopy, capillary electrophoresis (CE), liquid chromatography (LC), UV spectrophotometry and so on [11-15]. The great advantage of UV-Vis spectrophotometry is that this method can handle compounds with lower solubility and lower sample concentrations [15]. It is obvious that the usage of hydrazones is mostly as a result of biological activity which depends on the $\mathrm{pH}$ values of the media. For this reason, the objective of this study was to investigate the acid-base behavior of some aromatic hydrazones in basic media and to determine the dissociation constant values. The UV-Vis spectroscopic method was applied in order to observe changes in the UV spectra varying the $\mathrm{pH}$ of the media.

\section{EXPERIMENTAL \\ 2.1. Chemicals and instrumentation}

The investigated hydrazones were purified by twice recrystallization from ethanol or diluted ethanol. Purity was tested by measuring the melting point as well as by

*jankulovska_m@yahoo.com 
elemental analysis. The other chemicals $(\mathrm{NaOH}$, $\mathrm{NaClO}_{4}$ and ethanol) were of analytical grade p.a. (Alkaloid) and were used without further purification. A digital $\mathrm{pH}$ meter with glass electrode $(\mathrm{pH}$ range from 7 to 14) was used for measurements of the $\mathrm{pH}$ values of the solutions. The spectral measurements were carried out on a Varian Cary 50 spectrophotometer controlled by a computer and equipped with a $1 \mathrm{~cm}$ path length quartz cell, in the wavelength region from $190 \mathrm{~nm}$ to $400 \mathrm{~nm}$. The maximum scan rate was $24000 \mathrm{~nm} / \mathrm{min}$ and resolution was $1.5 \mathrm{~nm}$. An Excel program was applied for the calculation of the dissociation constants, while the UV spectra were obtained with the computer program Grams Version 4.10.Cl.

\subsection{Preparation of solutions}

A stock solution of the hydrazones was prepared by dissolving about $60 \mathrm{mg}$ of the investigated compounds in $96 \%$ ethanol in a volumetric flask of $250 \mathrm{~cm}^{3}$. The volume of $0.75 \mathrm{~cm}^{3}$ of this solution was transferred into $25 \mathrm{~cm}^{3}$ volumetric flask, and after adding an appropriate volume of $\mathrm{NaOH}\left(c=0.5 \mathrm{~mol} \mathrm{dm}^{-3}\right)$ and $\mathrm{NaClO}_{4}(c=1 \mathrm{~mol} \mathrm{dm}-3)$ the flask was diluted up to the mark with deionized water. The degree of dilution of the stock solutions was chosen to obtain the concentration of hydrazones in the test solution of about $3 \cdot 10^{-5} \mathrm{~mol} \mathrm{dm}^{-3}$ i.e. the absorbance to have a value between 0.1 and 1 at the studied wavelengths. The $\mathrm{pH}$ of the test solutions was adjusted with $\mathrm{NaOH}$, while the ionic strength was maintained constant (0.5 mol $\mathrm{dm}^{-3}$ ) using the solution of $\mathrm{NaClO}_{4}$. The UV spectra were taken immediately after preparation of the test solutions, at room temperature. After that the $\mathrm{pH}$ of each test solution was measured. The solution which did not contain the investigated hydrazone, but had the same composition as the tested one was used as a blank. The stock solutions were stable for a long period of time under ordinary conditions, while the stability of the working solution was satisfactory for only 24 hours.

\section{RESULTS AND DISCUSSION}

\subsection{Structure of investigated hydrazones}

The aromatic hydrazones investigated in this study share the general structural formula presented in Table 1. The investigated hydrazones were synthesized in our laboratory and structurally characterized by UV spectroscopy, infrared spectroscopy (IR), nuclear magnetic resonance $\left({ }^{1} \mathrm{H}\right.$ NMR and ${ }^{13} \mathrm{C}$ NMR), as well as by the elemental analysis [16].

Table 1. Structural formula of investigated hydrazones $\left(\mathrm{H}_{1}-\mathrm{H}_{5}\right)$

\begin{tabular}{|c|l|c|}
\hline \multicolumn{2}{|c|}{$\mathrm{R}$} & $\mathrm{R}^{\prime}$ \\
\hline Compound & \multicolumn{1}{|c|}{} \\
\hline $\mathrm{H}_{1}$ & $-\mathrm{H}$ & \\
\hline $\mathrm{H}_{2}$ & $-\mathrm{CH}_{3}$ & \\
\hline $\mathrm{H}_{3}$ & $-\mathrm{NO}_{2}$ \\
\hline $\mathrm{H}_{4}$ & $-\mathrm{Cl} \mathrm{R}_{3}$ & \\
\hline $\mathrm{H}_{5}$ & $-\mathrm{OH}$ & \\
\hline
\end{tabular}

297
IUPAC names of investigated compounds are: $\mathrm{H}_{1}$ : N-p-nitrobenzaldehydebenzoylhydrazone, $\mathrm{H}_{2}$ : N-pnitrobenzaldehyde- $p$-methylbenzoylhydrazone, $\quad \mathrm{H}_{3}$ : $\mathrm{N}-p$-nitrobenzaldehyde- $p$-methoxybenzoylhydrazone, $\mathrm{H}_{4}$ : N-p-nitrobenzaldehyde-p-chlorobenzoylhydrazone and $\quad \mathrm{H}_{5}$ : $\quad \mathrm{N}-p$-nitrobenzaldehyde- $p$ hydroxybenzoylhydrazone.

\subsection{UV spectra}

UV spectrophotometric measurements for investigated hydrazones $\mathrm{H}_{1}-\mathrm{H}_{5}$ were performed in the $\mathrm{pH}$ region between 7 and 14. The UV spectra were recorded in aqueous solutions containing 3\% ethanol $(v / v)$ at constant ionic strength of $0.5 \mathrm{~mol} / \mathrm{dm}^{3}$ (Figures 1 and 2).

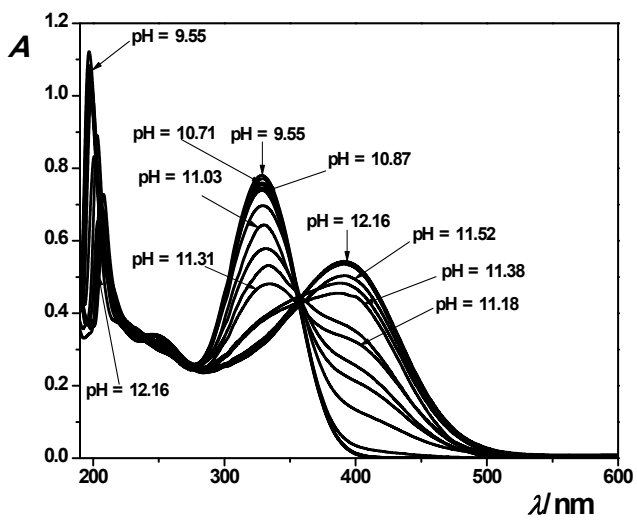

Figure 1. UV spectra of $N$-p-nitrobenzaldehydebenzoylhydrazone $\left(\mathrm{H}_{1}\right)\left(c=3.05 \cdot 10^{-5} \mathrm{~mol} / \mathrm{dm}^{3}\right)$ in $\mathrm{pH}$ region from 9.5 to 12.1 and ionic strength of $0.5 \mathrm{~mol} / \mathrm{dm}^{3}$

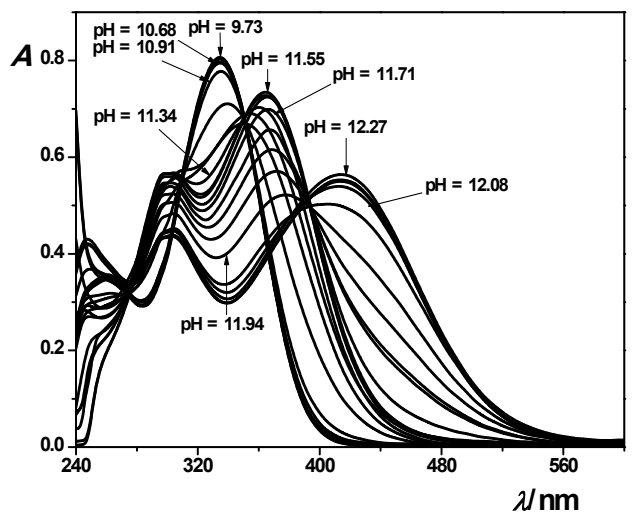

Figure 2. UV spectra of $N$ - $p$-nitrobenzaldehyde- $p$ hydroxybenzoylhydrazone $\left(\mathrm{H}_{5}\right)\left(c=3.11 \cdot 10^{-5} \mathrm{~mol} / \mathrm{dm}^{3}\right)$ in $\mathrm{pH}$ region from 9.7 to 12.3 and ionic strength of $0.5 \mathrm{~mol} / \mathrm{dm}^{3}$

Two absorption bands with maximum at around 195 and $330 \mathrm{~nm}$ were observed in the UV spectra of investigated hydrazones (Figs. 1 and 2). The appearance of the absorption band at around 195-200 $\mathrm{nm}$ is due to a $\pi \rightarrow \pi^{*}$ electronic transition in benzene ring, while the absorption band at around $330 \mathrm{~nm}$ is as a result of $n \rightarrow \pi^{*}$ electron transition in the azomethine group [17]. For further investigation we followed the 
changes in the absorption band that appeared at wavelength around $330 \mathrm{~nm}$.

From Fig 1 it can be noticed that the intensity of this band decreased when the basicity of the solution increased. In basic media, a bathochromic shift was observed probably as a result of the influence of basicity of the solution. Similar changes were observed in the UV spectra of hydrazones $\mathrm{H}_{2}-\mathrm{H}_{4}$. Difference in behavior was noticed in the UV spectra of hydrazone $\mathrm{H}_{5}$ (Fig. 2). The intensity of the absorption band decreased when the basicity of the solution increased and, at the same time, the bathochromic shift was observed. The absorption maximum reaches the position at $328 \mathrm{~nm}$ wavelength at a $\mathrm{pH}$ value of 9.8 and further changes were not observed until a $\mathrm{pH}$ of 11.1. At a higher $\mathrm{pH}$ value, the intensity of the absorption band again decreased and another bathochromic shift of about $6 \mathrm{~nm}$ was observed. This behavior of hydrazone $\mathrm{H}_{5}$ was expected because of the presence of a phenolic group in its molecule.

The position of the absorption maxima of the investigated aromatic hydrazones in basic media at ionic strength of $0.5 \mathrm{~mol} / \mathrm{dm}^{3}$, as well as the $\mathrm{pH}$ region of dissociation are listed in Table 2.

Table 2. Position of absorption maxima and $\mathrm{pH}$ region of dissociation of investigated hydrazones

\begin{tabular}{|c|c|c|c|c|c|c|}
\hline \multirow{2}{*}{ Comp. } & \multicolumn{3}{|c|}{ Electroneutral form } & \multicolumn{3}{|c|}{ Dissociated form } \\
\hline & $\mathrm{pH}$ & $\lambda_{\max }$ & $\lambda_{2 \max }$ & $\mathrm{pH}$ & $\lambda_{\max }$ & $\lambda_{2 \max }$ \\
\hline $\mathrm{H}_{1}$ & 9.5 & 196 & 328 & 11.67 & 198 & 390 \\
\hline $\mathrm{H}_{2}$ & 9.4 & 198 & 330 & 11.74 & 198 & 392 \\
\hline $\mathrm{H}_{3}$ & 9.6 & 198 & 334 & 12.06 & 198 & 394 \\
\hline $\mathrm{H}_{4}$ & 9.8 & 198 & 328 & 12.05 & 198 & 392 \\
\hline \multirow{2}{*}{$\mathrm{H}_{5}$} & \multirow{2}{*}{9.7} & \multirow{2}{*}{198} & \multirow{2}{*}{336} & 11.55 & 198 & 362 \\
\hline & & & & 12.15 & 198 & 414 \\
\hline \multicolumn{7}{|c|}{ pH region of dissociation } \\
\hline $\mathrm{H}_{1}$ & \multicolumn{6}{|c|}{$10.8-11.5$} \\
\hline $\mathrm{H}_{2}$ & \multicolumn{6}{|c|}{$10.8-11.6$} \\
\hline $\mathrm{H}_{3}$ & \multicolumn{6}{|c|}{$10.8-11.5$} \\
\hline $\mathrm{H}_{4}$ & \multicolumn{6}{|c|}{$10.9-11.6$} \\
\hline \multirow{2}{*}{$\mathrm{H}_{5}$} & \multicolumn{6}{|c|}{$10.9-11.3$} \\
\hline & \multicolumn{6}{|c|}{$11.7-12.1$} \\
\hline
\end{tabular}

\subsection{Determination of $\mathrm{p} K_{\mathrm{HA}}$ values}

The determination of $\mathrm{p} K_{\mathrm{HA}}$ values was made graphically and numerically. The calculations were made from the absorbance data at constant ionic strengths [18]. The dissociation constants were determined numerically according to following equation:

$$
\mathrm{p} K_{\mathrm{HA}}=\mathrm{n} \cdot \mathrm{pH}+\log I
$$

where, $\mathrm{p} K_{\mathrm{HA}}$ is the dissociation constant, $I$ is the ionization ratio $\left(I=\left(c(\mathrm{HA}\right.\right.$ neutral form $) / c\left(\mathrm{~A}^{-}\right.$ dissociated form)), and $\mathrm{n}$ is number of transferred protons

When $c(\mathrm{HA})=c\left(\mathrm{~A}^{-}\right)$, the ionization ratio is zero $(\log I=0)$, then the dissociation constant is obtained as an intercept of linear dependence on $\log I v s$. $\mathrm{pH}$ (Table 3).

Statistical data (standard deviation (SD), relative standard deviation (RSD), coefficient of determination $\left(R^{2}\right)$ ), as well as the range in which the obtained results are placed with confidence level of 0.05 (95\%) were calculated, too (Table 3).

Table 3. $\mathrm{p} K_{\text {HA }}$ values of investigated hydrazones and statistical data (SD, RSD, $R^{2}$ )

\begin{tabular}{|c|c|c|c|}
\hline \multirow{2}{*}{ Comp. } & \multicolumn{3}{|c|}{$\mathrm{p} K_{\mathrm{HA}}$ numerically } \\
\hline & $\mathrm{p} K_{\mathrm{HA}}$ & $\mathrm{SD}$ & RSD \\
\hline $\mathrm{H}_{1}$ & $11.26 \pm 0.03$ & 0.04 & 0.39 \\
\hline $\mathrm{H}_{2}$ & $11.16 \pm 0.03$ & 0.04 & 0.36 \\
\hline $\mathrm{H}_{3}$ & $11.22 \pm 0.03$ & 0.05 & 0.47 \\
\hline $\mathrm{H}_{4}$ & $11.12 \pm 0.02$ & 0.04 & 0.33 \\
\hline \multirow{3}{*}{$\mathrm{H}_{5}$} & $1^{*} 11.12 \pm 0.01$ & 0.01 & 0.07 \\
\hline & $2^{*} 12.11 \pm 0.03$ & 0.04 & 0.34 \\
\hline & \multicolumn{2}{|c|}{ pK KA graphically } & $R^{2}$ \\
\hline $\mathrm{H}_{1}$ & \multicolumn{2}{|c|}{11.24} & 0.966 \\
\hline $\mathrm{H}_{2}$ & \multicolumn{2}{|c|}{11.17} & 0.962 \\
\hline $\mathrm{H}_{3}$ & \multicolumn{2}{|c|}{11.25} & 0.958 \\
\hline $\mathrm{H}_{4}$ & \multicolumn{2}{|c|}{11.18} & 0.976 \\
\hline \multirow{2}{*}{$\mathrm{H}_{5}$} & \multicolumn{2}{|c|}{11.13} & 0.996 \\
\hline & \multicolumn{2}{|c|}{12.20} & 0.896 \\
\hline
\end{tabular}

${ }^{1}$ dissociation of phenolic group

${ }^{2}$ dissociation of amide group

The $\mathrm{p} K_{\mathrm{HA}}$ values obtained numerically have identical values to those estimated graphically (Table 3 ). The dependence of $\log I$ vs. $\mathrm{pH}$ is linear with the coefficient of determination $\approx 1$ suggesting satisfactory precision in the determination of dissociation constants graphically. This implies that the $\mathrm{p} K_{\mathrm{HA}}$ values can be successfully determined in both ways. From the results presented in Table 3 it can be seen that there are no differences in $\mathrm{p} K_{\mathrm{HA}}$ values of hydrazones $\mathrm{H}_{1}-\mathrm{H}_{4}$ which referred to the dissociation of amide group. This result probably is a result of a similar structure of investigated hydrazones suggesting that the influence of substituents $\left(-\mathrm{CH}_{3},-\mathrm{OCH}_{3},-\mathrm{Cl}\right.$ and $-\mathrm{OH})$ is not significant. The dissociation process of hydrazone $\mathrm{H}_{5}$, as it was mentioned before, takes place in two steps. The first step is due to the dissociation of the phenolic group which is a stronger acid, while the second step is as a result of dissociation of the amide group. For this reason, the constant value of dissociation, which referred to the dissociation of the amide group, is higher in comparison with the investigated hydrazones $\mathrm{H}_{1}-\mathrm{H}_{4}$. These differences are due to the presence of the phenolic group in the molecule of hydrazone $\mathrm{H}_{5}$, which caused a late dissociation of the amide group [19].

\section{CONCLUSION}

The dissociation process of some aromatic hydrazones was followed using UV spectroscopy. The observed changes in the UV spectra showed that the reaction of dissociation occurred in one $\left(\mathrm{H}_{1}-\mathrm{H}_{4}\right)$ or two steps $\left(\mathrm{H}_{5}\right)$ depending of the structure of hydrazones. The observed $\mathrm{pH}$ range of the first step of dissociation it was from 10.8 to 11.6 , while for the second step was 11.7-12.1. The changes in the UV spectra were used to calculate the $\mathrm{p} K_{\mathrm{HA}}$ values. The $\mathrm{p} K_{\mathrm{HA}}$ values were determined graphically and numerically from the absorbance data. The similarity of the $\mathrm{p} K_{\mathrm{HA}}$ values suggested that the substituents have no important influence on the dissociation process. There was a good agreement between the $\mathrm{p} K_{\mathrm{HA}}$ values of the investigated 
hydrazones and those of similar classes of compounds [20].

\section{REFERENCES}

1. L. N. Suvarapu, Y. K. Seo, S. Baek, V. R. Ammireddy, "Review on Analytical and Biological Applications of Hydrazones and their Metal Complexes," E-Journal of Chemistry, vol. 9, no. 3, pp. 1288-1304, Dec. 2011. DOI: 10.1155/2012/534617

2. S. Rollas, S. G. Kücükgüzel, "Biological Activities of Hydrazone Derivatives," Molecules, vol.12, no. 8, pp. 1910-1939, Aug. 2007.

DOI: $10.3390 / 12081910$ PMid: 17960096

3. G. Verma, A. Marella, M. Shaquiquzzaman, M. Akhtar, M. R. Ali and M. M. Alam, "A review exploring biological activities of hydrazones," J. Pharm. Bioallied. Sci., vol. 6, no. 2, pp. 69-80, Mar. 2014. DOI: $10.4103 / 0975-7406.129170$

PMid: 24741273

PMCid: PMC 3983749

4. M. Asif and A. Husain, "Analgesic, Anti-Inflammatory, and Antiplatelet Profile of Hydrazones Containing Synthetic Molecules,” J. Appl. Chem., vol. 2013, pp. 1-7, Oct. 2013.

DOI: $10.1155 / 2013 / 247203$

5. R. Narisetty, K. B. Chandrasekhar, S. Mohanty, B. Balram, "Synthesis and Antimicrobial Evaluation of Some Novel Hydrazone Derivatives of 2,5-Diflurobenzoic acid," Lett. Drug Des. Discov., vol. 10, no. 7, pp. 620-624, 2013. DOI: $10.2174 / 1570180811310070009$

6. L. H.S. A. Terra, M. C.C. Areias, I. Gaubeur, M. E. V. Suez-Iha, "Solvent ExtractionSpectrophotometric Determination of Nickel(II) in Natural Waters Using DI-2-Pyridyl Ketone Benzoylhydrazone," Spectrosc. Lett., vol. 32, no. 2, pp. 257-271, Mar. 1999.

DOI: $10.1080 / 00387019909349981$

7. M. Liu, Y. Wang, W. Wangyang, F. Liu, Y. Cui, Y. Duan, M. Wang, S. Liu, C. Rui, "Design, synthesis, and insecticidal activities of phthalamides containing a hydrazone substructure," J. Agric. Food Chem., vol. 58, no. 9 pp. 6858-6863, Jun. 2010

DOI: $10.1021 /$ jf10oog19

PMid: 20450195

8. J. K. Sears, J. R. Darby, The Technology of Plasticizers, 2nd ed., New York (NY), USA: John Wiley \& Son, 2003.

9. R. C. Maurya and S. Rajput, "Neutral dioxovanadium(V) complexes of biomimetic hydrazones ONO donor ligands of bioinorganic and medicinal relevance: Synthesis via air oxidation of bis(acetylacetonato)oxovanadium(IV), characte-rization, biological activity and 3D molecular modeling," J. Mol. Struct., vol. 833, no. 1, pp. 133-144, May 2007. DOI: 10.1016/j.molstruc.2006.09.022

10. M. F. Fathalla, S. N. Khattab, "Spectrophotometric determination of $\mathrm{pKa}$ 's of 1-Hydroxybenzotriazole and Oxime Derivatives in 95\% Acetonitrile-Water," $J$ Chem. Soc. Pak., vol. 33, no. 3, pp. 324-332, Jun 2011. Retrieved from: http://jcsp.org.pk/ArticleUpload/2280-10260-1-CE.pdf
Retrieved on: Feb. 10, 2017

11. K. Zarei, M. Atabati, E. Abdinasab, "Spectrophotometric Determination of Conditional Acidity Constant of Some Sulfonephthalein Dyes as A Function of Anionic, Neutral and Cationic Surfactants Concentrations Using Rank Annihilation Factor Analysis," Eurasian J. Anal. Chem., vol. 4, no. 3, pp. 314-327, Oct. 2009. DOI: $10.12973 /$ ejac.2009.00076a

12. K. K. Chandrul, B. Srivastava, "A process of method development: A chromatographic approach," J. Chem. Pharm. Res., vol. 2, no. 2, pp. 519-545, Sep. 2010.

Retrieved from:

http://www.jocpr.com/articles/a-process-of-methoddevelopment-a-chromatographic-approach.pdf Retrieved on: Feb. 10, 2017.

13. J. Comer, K. Box, "High-Throughput Measurement of Drug $\mathrm{pK}_{\mathrm{a}}$ Values for ADME Screening," $J$. of Lab. Automation, vol. 8, no. 1, pp. 55-59, Feb. 2003. DOI: $10.1016 / \mathrm{S} 1535-5535-04-00243-6$

14. B. Pathare, V. Tambe, S. Dhole and V. Patil, "An update on various analytical techniques based on UV spectroscopy used in determination of dissociation constant," Int. J. Pharm., vol. 4, no. 1, pp. 278-285, 2014.

Retrieved from:

http://pharmascholars.com/pharma/upload/pharmacy 52e146ff685f4.pdf

Retrieved on: Feb. 14, 2017.

15. M. Jankulovska, K. Čolančeska-Ragenovik, V. Dimova, I. Spirevska, P. Makreski, "Synthesis and characterization of new $p$-substituted aromatic hydrazones," Org. Chem.: An Ind. J., vol. 8, no. 9, pp. 326-334, Feb. 2012.

Retrieved from:

http://www.tsijournals.com/articles/synthesis-andcharacterization-of-new-psubstituted-aromatichydrazones.pdf

Retrieved on: Feb. 14, 2017

16. E. L. Kristallovich, A. G. Eshimbetov, V. D. Chuvylkin, L. I. Belenkii, Kh. M. Shakhidoyatov, "Nature of $\pi$-Electronic Transitions in UV Spectra of Deoxyvasicionone and Its Derivatives," Chem. Nat. Comp., vol. 39, no. 5, pp. 495-500, Sep. 2003. DOI: 10.1023/B:CONC.0000011127.28348.ca

17. M. Jankulovska, I. Spirevska, "Analysis of acid-base properties of some $p$-substituted aromatic hydrazones in aqueous perchloric acid by spectrophotometric and semiempirical methods," Maced. J. Chem. Eng., vol. 33, no. 1, pp. 85-96 Jan. 2014.

DOI: $10.20450 / \mathrm{mjcce} .2014 .370$

18. A. A. Salem, "Spectrophotometric and Potentiometric Characterization of Some Arylhydrazone Derivatives and their Applications in Lanthanide Determination," Microchem. J., vol. 6o, pp. 51-66, Mar. 1998.

DOI: $10.1006 /$ mchj.1998.1621

19. Ł. Popiołek, A. Chodkowska, A. Tryka, K. Pawłowski, M. Kiełczykowska, J. Kocot, M. Wujec, E. JagiełłoWójtowicz, "Synthesis, Dissociation Constants, and Some Pharmacological Properties of Schiff Base Hydrazones and their Cyclization to 1,3-Thiazolidin-4one Derivatives," J. Heterocycl. Chem., vol. 52, no. 5, pp. 1506-1512, Sep. 2015.

DOI: $10.1002 /$ jhet.2257 